and their place may be efficiently taken by admixture of Iresh serum to make it perfectly bacteriulytic to B. pestis. In other words, the complements of Roux's serum are destroyed by heat, while the amboceptor remains unaltered, and for the formation of a potent antibody necessary to produce the bacteriolysis of B. pestis an introduction of fresh rabbit's serum rieh in complement is essential. Further experiments have been made to show that the complement may be from the fresh blood of man, dog, rat, or monkey, and possibly from any other mammal. That Roux's serum is very rich in amboceptor is shown by the following experiment :

Heated Roux's serum was diluted with an indifferent serum: for example, heated rabbit's serum to the extent of $x$ in 240 , and a drop of this when mixed with a drop of fresh rabbit's serum has given result quite as good as a fresh plague, convalescent's serum when infected with the plague culture.

On a perusal of the foregoing remarks the question naturally would suggest itself why a serum like Roux's serum, rich in precipitin and equally rich in amboceptor. does not yield euch favourable result when applied to therapeutic use. One would at first sight expect that the complement or alexin naturally existing in a plague-infected individual would suffice to form a suitable antibody in combination with the ambo ceptor of Roux's serum, and a successful termination of the case would result. But the experience of all persons who have used this serum in India points no such hopeful issue. Could the complement of the plague patient at a certain stage of the disease be different from the normal complement? It is a well-known fact that after a certain stage of illness (in fatal cases) plague becomes septicaemic-that is, the blood of such patients shows per se bacilli, or at all events bacilli become demonstrable by culture. Here is an evidence of either a failure of amboceptor production or alteration of the complement or both, and this fact has been demonstrated by me in vitro -namely, that though a patient's blood may show marked production of bacteriolysis in the earlier stages of the disease, the blnod from the same patient becomes a very fertile soil to $B$. pestis towards the fatal termination of the case, even though the blood may be free from B. pestis. What is the actual observation gained by experiment on the subject?

For this purpose, two series of experiments were undertaken: first, to show the absence of amboceptor in dying cases of plague; and, secondly, the alteration of the complement in the blood of such a case; and I tabulate the result as follows:

A.

Heated Pl. convalescent's blood serum +rabbit's fresh serum $+\mathrm{Pl}=$ no growth.

Heated blood serum of a dying plague "case+rabbit's fresh serum +PI =rich growth.

B.

Fresh blood serum from ardying case $+\mathrm{Pl}=$ =ery rich growth.

Heated blood serum from a dying case + Roux's serum $+\mathrm{Pl}=$ good growth.

Roux's serum +fresh rabbit's serum + Pl. $=$ no growth

Fresh blood serum from dying case+Roux's serum + fresh rabbit's serum $+\mathrm{Pl} .=$ rich growth

The same result was obtained in 12 dying cases I have examined, and from this I am led to believe that the complement in a dying case of plague is not only ineflicient, but is altered in composition to the extent of neutralizing the complement effect of the fresh rabbit's serum. And, lastly, by a study of the plague bloods as indicated above, it appears to me that changes in a dying plague case occur in the following order :

I. Appearance of amboceptor.

2. Disappearance of the amboceptor and commencement of septicaemia.

3. Disappearance of complement.

4. Alteration of complement in the form of possibly an anticomplement.

Further proof that the blood serum of such cases does undergo fundamental biochemical changes, and the causes underlying these changes are, I believe, possible to demonstrate in vitro; but as the experiments are yet incomplete, I propose to defer this part of the subject for a future occasion.

Before concluding I cannot pass over the most vitally important problem why a suitable complement should not be tried along with a serum rich in amboceptor for therapeutic purposes. It is true one has to bear in mind that an organism in its last stages and under the intoxication of a virulent infection may find it too much to react to a complement coming from another species-for example, the horseand may break down in the effort to adjust itself on the entry of suish a complement foreign to it. But as one has to face the problem in extremis, such an attempt seems to me justifiable, and should an opportunity arise $I$ propose to put it to the clinical use at an early date.

I summarize the above considerations as follows :

1. The lysogenic action of $\mathrm{Pl}$. convalescent's blood to B. pestis is brought about by the combined action of two distinct bodies-

(a) One of the nature of amboceptor (not destroyed by heat up to $56^{\circ}$ C.), and

(b) The other of the nature of complement (destroyed at $56^{\circ} \mathrm{C}$.)

2. A serum from a plague convalescent loses its lysogenic action on $B$. pestis by age and exposure to light in a few days, and in a few minutes by exposure to $56^{\circ} \mathrm{U}$. (probably due to the destruction of complement).

3. This lost property is restored by a mixture of a fresh serum; for example, from the rabbit :(addition of complement).

4. Rabbits when suitably immunized to plague produce a serum rich in precipitins, and containing a fair amount of bacteriolysin (to $B$. pestis)

5. By exposure to heat of $56^{\circ} \mathrm{C}$. the bacteriolysis is rendered impotent (owing to destruction of complement); it is, however, to a certain extent restored by addition of fresh rabbit's blood serum (complement).

6. Roux's antipesteux serum is very rich in precipitin, but not particularly bacterioly tic to $B$. pestis as such.

7. This loss of bacteriolytic property is probably due to age, and is certainly produced by exposure to $56^{\circ} \mathrm{C}$. (owing probably to loss of complement).

8. By addition of fresh rabbit's, man's, rat's, etc., fresh serum, however, the bacteriolytic property is restored (freeh complement)

9. Blood serum of dying cases of plague is deficient in amboceptor, and its complement is not only poor but of the nature of an anti-complement.

REFERENCES.

British Medical Journal, December 20 th, 1902. 2 Bombay Medical and Physical Society's Journal, April, rgo2. 3 Ehrlich, Morganroth, Berl. klin. Woch., rgor. ${ }^{3}$ Bordet, Agglutination und Dissolution des Haematie. Bordet, Serums Haemolytique et Antitoxine, Ann. de l'Inst. Pasteur, 18g9; ibid, Metalnikoff, Spermatoxin et Antispermatoxin ibid. Metchnikoff, Sur les Cytotoxins, ibid , 889 and 1900 . Metchnikoff and Besredka, Action de l'Haemotoxine sur l'Homme, ibid., r900. Weichardt, Sur Antispermotoxin, ibid., rgor. Bulloch, Practitioner, rgor. Professor Welch's Huxley Lecture, BRITISH MEdICAL JOURNAL, 1902. 4 Bombay Medical as:d Physical Society's Journal, August, 1902.

\section{THE USE OF ANTITOXIN IN THE TREATMENT AND PREVENTION OF DIPHTHERIA.}

BY ROBERT DAWSON RUDOLF, M.D.EDIN., M.R.C.P.LOND.,

Lecturer on Medicine and Clinical Medicine in the University of Toronto.

THE object of this short communication is to give the results of our experience with diphtheria antitoxin in the isolation wards of the Victoria Hospital for Sick Children of Toronto $(a)$ in the treatment, $(b)$ in the prevention of diphtheria.

1. Daring 1901 there were an unusually large number of cases of diphtheria in the hospital. In spite of every possible care being taken, every now and then a case would be admitted while in the incubation period, and although suspicious cases were immediately isolated, the disease would spread. We had during I901, then, about I00 cases of the disease, all proved bacteriologically to be diphtheria. All of them, except a few very mild ones, were treated from the outset with antitoxin, and only 3 died, and 1 of these was complicated with scarlet fever. Unfortunately, no actual note was kept of the number of cases during that year; and although I believe that 100 very nearly represents the total; still the percentage of deaths loses most of its value, and $I$ only give it as a general statement. The number of deaths is accurate.

Since January 18t, 1902, we have kept a book in which all cases have been entered, with details as to age, sex, number of days ill before being admitted to the infectious wards, treatment, etc., and from this book I take the following facts :

Between January rst and July 7 th there were $42^{\prime}$ cases of diphtheria admitted to the infectious wards, all of which showed the Klebs-Loeffler bacillus. In nebrly all cases the 
bacillus has been of the short variety. All except a few of the mildest were given antitoxin at once on admission, frequently before the bacteriological report had been received, the initial dose varying from 1,500 to 4,000 units. The dose was repeated in a few hours it required. In addition, the throat cases had their fauces painted with Loeffler's solution of menthol and sesquichloride of iron, and where the nose was affected a spray of very dilute corrosive sublimate was used.

Of the 42 cases thus treated, $4 \mathrm{I}$ recovered completely. One died, a girl aged 13 years, and some details of her case are as follows:

It seems that she had been in the city isolation hospital several weeks before, suffering from diphtheria. She was discharged in May, and was admitted to the Children's Hospital on June 12th for genu valgum. Her history states that she had "kidney disease," and her urine on admission contained albumen and casts. On June ${ }_{2} \mathrm{rd}$ she was sent into the diphtheria ward suffering from a mild attack of faucial diphtheria. So mild, indeed, was the case that she was not given antitoxin. A week later, when her throat was clear and her temperature normal, she developed uraemic symptoms, and died very quickly. She was given 3,000 units of antitoxin when the uraemia developed, in hopes of neutralizing the toxin that might be irritating the kidney, but no amelioration resulted. The necropsy [showed the kidneys to be contracted, markedly cirrhotic and white on section. The left weighed $5 \mathrm{dr}$. $12 \mathrm{gr}$., and the right 5 dr. $3^{6}$ gr.

It is thus scarcely fair to call this a case of death from diphtheria, although that disease undoubtedly precipitated the final result. If antitoxin had been early and freely used possibly that result might have been averted, as the cirrhosed kidneys might have been saved the toxic irritation; but one can only surmise on this point.

On the other hard, would the presence of renal disease have contraindicated the use of antitoxin? A large amount of literature exists upon the occurrence of albuminuria after the use of the serum. C. E. Michael, in a series of analyses from the returns of the Metropolitan Asylums Board of London in 1898 , found that the use of antitoxin in diphtheria increased the percentage of cases of albuminuria, but, on the other hand, decressed markedly the occurrence of nephritis. McCullom at the Boston City Hospital found that cases of albuminuria of diphtherial origin more often showed a decrease than an increase in the albuminuria after the use of antitoxin.

There was only one case of post-diphtherial paralysis-a very severe one, involving the muscles of déglutition and of all four extremities. It occurred in a boy of 14 years of age, who had a slight attack of nasal diphtheria as a complication of scarlet fever. So slight was the affection that no antitoxin was used. He recovered completely. Thus the only two of our cases that went wrong were cases in which the disease seemed so slight that antitoxin was not used. Beveral of the 42 cases were of a very severe type.

One, a boy of 7 years, was not admitted to the diphtheria wards until the fifth day of his illness. His swab had persistently shown only a streptococcus infection until then. His pharynx was most extensively involved, and the disease had spread into both nostrils. He was unconinvolved, and the disease had spread into both nostrils. He was uncon-
scious and delirious. The case looked hopeless, but he was given 4,000 units of antitoxin, and 6,coo more within the next twenty-four hours. He also received $20 \mathrm{c.cm}$. of antistreptococcus serum, as the infection was a mixed one. Improvement set in at once, and he recovered completely.

I am fully aware that one cannot dogmatize from the results of the use of antitoxin in 42 cases, but the series helps to swell the enormous mass of evidence in favour of the value of the serum in the treatment of diphtheria.

The most extensive report upon the use of antitoxin has been published by Dr. Otto Jelinek, of the State Institute for the preparation of diphtheria antitoxin in Vienna. ${ }^{2}$ He has collated the published reports of all observers in all parts of the world to the close of 1898 . Altogether he has records of 127,359 case of diphtheria in which the serum was used, with 18 o88 deaths-that is, 14.2 per cent. From an analysis of 52,521 cases, showing a death-rate of 15.28 per cent., he gives the following most convincing figures :

Those treated with antitoxin on the rst day had a mortality of $5.07 \%$

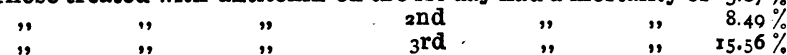

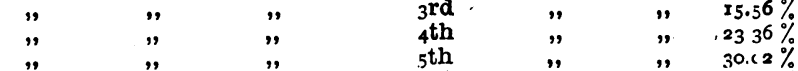

$$
\begin{aligned}
& \text { " " " " after the } 5 \text { th } \quad " \text { " " } 30.36 \%
\end{aligned}
$$

This table includes cases from all parts of the world, in all climates, in hospitals and private practice, amongst the poor and the well-to-do.

One might quote at any length from statistics published by different writers, but suffice it to say that they all tell the same tale of mortality reduced in proportion to the earliness of use and the quantity of antitoxin given.

2. The results of our employment of antitoxin in the prevention of diphtheria have, as far as they go, been equally striking.

In all institutions devoted to the care of children diphtheria is a frequent and dreaded scourge, and the Victoria Hospital for Children has been no exception to the rule. In spite of every precaution which could be thought of the institution has almost constantly had some diphtheria in it, and the Lady Superintendent informs me that during the five years that she has presided there there have never been two successive weeks in which the disease has been completely absent. Twice a year an exacerbation has regularly occurred, namely, when the children were moved over to the Summer Hospital on the Toronto Island in May, and when they returned to the city in October. The usual increase in cases occurred last June, and threatened to become more gerious than the average.

In the first week in July every individual in the hospital was given an immunizing dose of from 300 to 500 units of antitoxin, and the dose has been repeated every three weeks since. There are, on an average, 165 souls in the institution. Every new patient has been given a similar dose on admission, and every three weeks thereafter. The result has been most gratifying. Not a single case of diphtheria has occurred in the hospital since the immunizing treatment was commenced, that is, for a period of over five months. During this time the usual number of cases have been occurring elsewhere in Toronto.

Dr. William Goldie, the bacteriologist to the hospital, has on several occesions during the last few years examined swabs taken from the throats of healthy inmates of the hospital, and has always found that a considerable percentage of them showed the Klebs-Loeffler bacillus. He has made similar examinations recently, and finds that, as before, a percentage of apparently healthy throats show the bacillus. Thus the germ is present, but its hosts are immune, and hence no diphtheria occurs.

A large amount of literature is rapidly accumulating, showing the good results that follow the use of immunizing doses of antitoxin. A good summary of this evidence up to date is given by Northrup in his excellent article on diphtheria in Nothnagel's Encyclopaedia of Practical Medicine.

As regards the safety of using these immunizing doses of the serum, our experience has also been in accord with that of most observers. Altogether upwards of 1,oco doses have been administered by Drs. Graham, Wright, and Waters, the resident physicians of the hospital. They have been given to patients suffering from all kinds of disease, and yet in no instance have any serious symptoms been produced. Not a single local abscess has occurred. A certain percentage of the cases have shown eruptions, and in three instances these have been petechial. It is interesting to note that the resident physicians have found that the eruptions occur almost exclusively after the first injections; a few have appeared after the second, and none later on. This point does not seem to have been remarked before.

Our experience with antitoxin, then, would lead us to the following conclusions :

I. Every case of diphtheria should be treated with antitoxin. As a rule, the diagnosis is easily made clinically, and it is better in such cases not to wait for the bacteriological report, but to inject the serum at once. Then, if the diagnosis is confirmed by the bacteriologist, one has "stolen a march" of several hours on the disease; if the case proves not to have been diphtherial, one has at least done no harm.

2. The serum should be administered not only early, but also freely, 3,oco units being an average first dose.

3. This use of antitoxin in no way interferes with the enployment of any medicinal or other treatment which may be indicated, but all the latter are of secondary importance during the first few days of the illness.

4. All individuals who are exposed to infection should be given immunizing doses of antitoxin, just 8.8 ali people who run the rikk of small-pox infection should be vaccinated.

5. Five hundred units is the ordinary immunizing dose, but 300 seems to be sufficient for children under 2 years of age. The dose should be repeated at least every three weeirs while any danger of infection lasts.

\section{REFERENCE,}

1 Das Oesterreichsches Sanitatswesen, No. 52, 19:0, quoted by American Medicine, April 13th, rgor. 